\title{
AN APPLICATION OF HYDROLOGIC METHODOLOGY TO THE INTERNAL DOSE CALCULATION: THE INTAKE OF RADIOACTIVITY ON AGRICULTURAL PRODUCTS DERIVED FROM FALLOUT
}

\author{
Syota SASAKI ${ }^{1} \cdot$ Hayase YONEDA ${ }^{2} \cdot$ Tadashi YAMADA $^{3} \cdot$ Tomohito J. YAMADA $^{4}$ \\ ${ }^{1}$ Student Member of JSCE, M. Eng., Civil Engineering Course, Graduate School of Science and Engineering, Chuo \\ University (1-13-27 Kasuga, Bunkyo-ku, Tokyo, 112-8551, Japan) \\ 2 Member of JSCE, M. Eng., CTI Engineering Co., Ltd. (CTI Saitama Bldg., 1-14-6 Kamikizaki, Urawa-ku, Saitama, \\ Saitama, 330-0071, Japan) \\ ${ }^{3}$ Fellow Member of JSCE, Dr. of Eng., Dept. of Environment and Civil Engineering, Faculty of Science and \\ Engineering, Chuo University (1-13-27 Kasuga, Bunkyo-ku, Tokyo, 112-8551, Japan) \\ ${ }^{4}$ Member of JSCE, Dr. of Eng., Division of Field Engineering for the Environment, Faculty of Engineering, \\ Hokkaido University (Kita 13, Nishi 8, Kita-ku, Sapporo, Hokkaido, 060-8628, Japan)
}

\begin{abstract}
This paper presents a readily understandable hydrologic-based method to calculate the effective dose emerges from the intake of radioactivity on agricultural products derived from radioactive fallout on the soils. We discuss the intake of polished rice as an example of agricultural product. The authors have been studied internal dose calculation regarding to the human body. The scope of our research is expanded from the human body to the soils in this report. Our modeling of the radiocesium transfer from the soils to the human body is based on the previous research regarding the vertical infiltration, the transfer factor to plants, and the residence time of cesium in the soils. We calculate analytically in concise formalization the intensity of radioactivity on the soils per area and the effective dose derived from the intake of radioactivity on the rice using measured radioactive fallout after the Fukushima Daiichi NPP accident.
\end{abstract}

Key Words: Fukushima Daiichi NPP accident, radioactive fallout, intake of radiocesium, internal dose calculation, radiation protection

\section{INTRODUCTION}

\section{(1) Research background}

The Great East Japan Earthquake attacked the north-east region area in Japan on March 11, 2011. From the damaged reactor containment vessels, several radioisotopes have leaked and have been diffused in the north-east region. After the accident, radioactive fallout into agricultural land leaked from the reactor was observed. Thus, health damage caused by radioactivity on food supply has become an issue of great interest both scientifically and socially. On April, 2012, Japanese government revised the regulatory value of radiocesium on general food from 500 $\mathrm{Bq} / \mathrm{kg}$ to $100 \mathrm{~Bq} / \mathrm{kg}$. Japanese government claims that the revision of standard limit for radiocesium is not emergency response to the nuclear accident but long-term measures. The Japanese regulation regarding radioactivity on food is, however, several times stricter than that of other countries. The lack of practical knowledge concerning health issues associated with radioactive contamination has caused excessive anxiety to the public inside and outside Japan.

\section{(2) Objectives}

We have been studied hydrologic-based internal dose calculation ${ }^{1), 2)}$. In this paper, we aim to expand the scope of the research from the human body to the soils. We restrict ourselves to the cesium-137 absorption of radioactivity from the soils to agricultural products here. It should be noted that direct deposition of radiocesium into agricultural products is not discussed. We model the transfer of radiocesium from the radioactive fallout into the soils to the intake of radioactivity on agricultural products. Subsequently, we calculate the effective dose by applying the methods we have been previously studied. We show that our hydrologic-based method can be straightforwardly applied to not only the human body but also the soils.

\section{THEORY AND METHODS}

(1) Modeling of transfer from radioactive fallout to radioactivity on agricultural products

Nuclear Regulation Authority opens the monthly radioactive fallout to the public ${ }^{3)}$. We consider the transfer 
(a) Radioactive fallout of radiocesium:

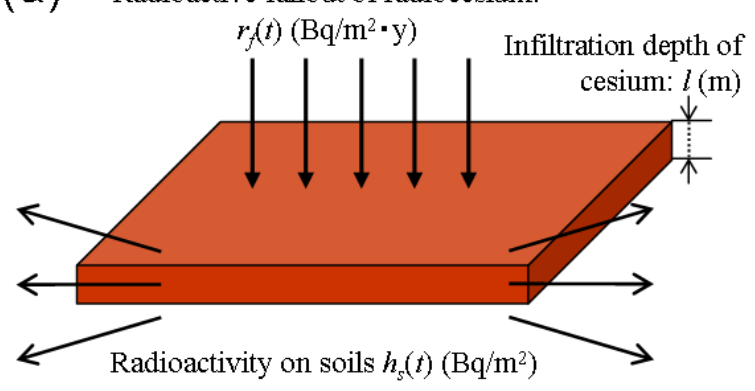

(b)

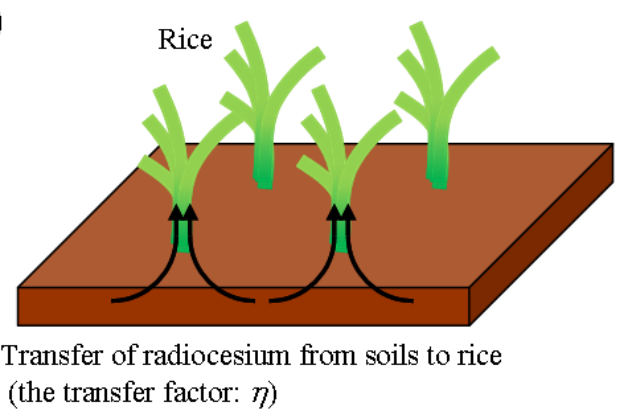

(c)

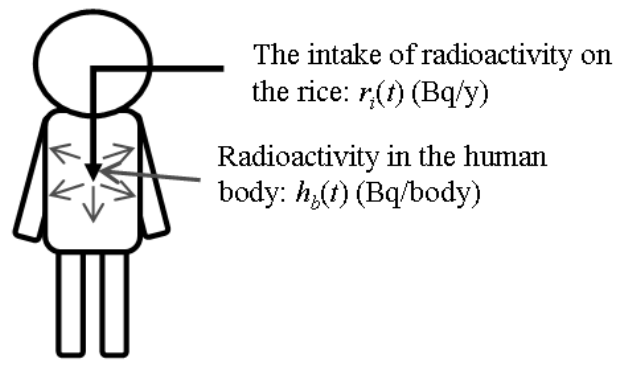

Fig.1 Schematic diagrams of the radiocesium transfer, (a) from the radioactive fallout to the soils, (b) from the soils to the rice and (c) the intake of radioactivity on the rice.

of radiocesium from the soils to the intake of radioactivity on agricultural products by using the data of fallout. Fig.1 shows a schematic diagrams of the radiocesium transfer. Fig.1(a) describes radiocesium fallout into the soils. We can know the actual intensity of radioactivity per area from above mentioned data of Nuclear Regulation Authority ${ }^{3)}$.

Fig.1(b) describes the transfer of radiocesium from the soils to rice, one of the major agricultural product in Japan. Here, we introduce the transfer factor $\eta$ defined as:

$$
\eta=\frac{\begin{array}{c}
\text { The concentration of radioactivity } \\
\text { in agricultural products }(\mathrm{Bq} / \mathrm{kg})
\end{array}}{\text { The concentration of radioactivity }} .
$$

There are many reports regarding the transfer factor ${ }^{4), 5), 6)}$. The unit conversion from intensity of radioactivity per area $\left(\mathrm{Bq} / \mathrm{m}^{2}\right)$ to the concentration of radioactivity in the soils $(\mathrm{Bq} / \mathrm{kg})$ is also required. Later, their treatment in this paper is described in detail.

Fig.1(c) describes the intake of radiocesium on the rice. We can calculate the effective dose by using the method the

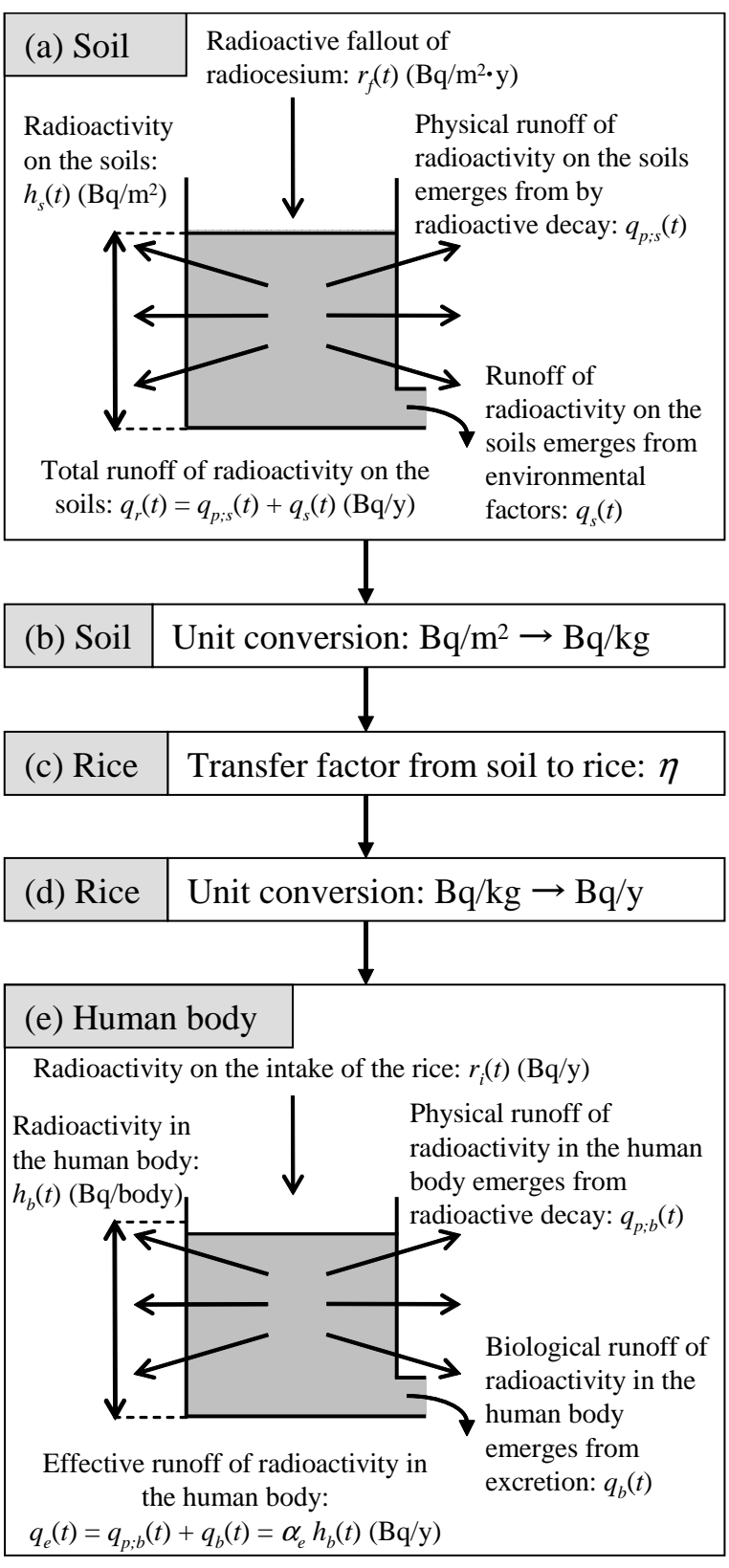

Fig.2 The flowchart to calculate radioactivity in the human body from the radiocesium fallout through the soils and rice.

authors proposed earlier ${ }^{1), 2)}$. Thus, the transfer of radiocesium from the fallout to the the human body is described schematically in this section.

\section{(2) The attenuation of radioactivity on the soils}

In the followings, we consider the procedure of the calculation. Fig. 2 shows the flowchart to calculate radioactivity in the human body from the radiocesium fallout through the soils and the rice. At first, we can know the fallout of radiocesium from the above mentioned data ${ }^{3}$. The intensity of radioactivity per area on the soils $h_{s}(t)$ is calculated from the residence half-time $T_{r}$, which is defined as the time the intensity of radioactivity on the soils decreases by half, and so: $h_{s}\left(T_{r}\right)=h_{s}(0) / 2$. The specific value of $T_{r}$ is referenced previous studies ${ }^{7,8), 9)}$. 
The existence of residence half-time suggests that intensity of radioactivity per area on the soils decreases exponentially. That is, runoff of radioactivity on the soils is also proportional to the storage. The authors have studied the method to calculate intensity of radioactivity in the human body by solving first order linear ordinary differential equation $^{2)}$. Here, we suggests that intensity of radioactivity on the soils also can be described by first order linear ordinary differential equation. This is the aim of this paper, we attempt to expand the subject of our method from the human body to the soils.

From the definition, the relationship between half-life $T$ and attenuation constant $\alpha$ is defined as:

$$
T=\frac{\ln 2}{\alpha} \text {. }
$$

For example, it is satisfied that $T_{r}=\frac{\ln 2}{\alpha_{r}}$. We should note the correspondence of subscripts in the followings.

Recall that again, intensity of radioactivity per area on the soils decreases exponentially and runoff is linear with respect to the storage. That is,

$$
q(t)=-\frac{d h(t)}{d t}=-\frac{d}{d t} h_{0} e^{-\alpha t}=\alpha h(t),
$$

where $h_{0}=h(0)$ is introduced for convenience. Fig.2(a) gives the relationship of total runoff $q_{r}(t)$ with physical runoff $q_{p ; s}(t)$ and runoff by environmental factors on the soils $q_{s}(t)$ as:

$$
q_{r}(t)=q_{p ; s}(t)+q_{s}(t)=\left(\alpha_{p}+\alpha_{s}\right) h_{s}(t)=\alpha_{r} h_{s}(t),
$$

that is, the relationship between residence half-time $T_{r}$, physical half-life $T_{p}$, and "half-life on the soils" (named here for convenience) $T_{s}$ is:

$$
\frac{1}{T_{r}}=\frac{1}{T_{p}}+\frac{1}{T_{s}}
$$

From Fig.2(a), we can denote the continuity equation of radioactivity in the soils as:

$$
\frac{d h_{s}(t)}{d t}=r_{f}(t)-q_{r}(t)
$$

From Eq.(4), Eq.(6) is rewritten as:

$$
\frac{d h_{s}(t)}{d t}=r_{f}(t)-\alpha_{r} h_{s}(t)
$$

that is a first order linear ordinary differential equation. We can get the solution of Eq.(7) analytically as:

$$
h_{s}(t)=\int_{0}^{t} e^{-\alpha_{r}(t-\tau)} r_{f}(\tau) d \tau+h_{s 0} e^{-\alpha_{r} t}
$$

under the initial condition $h_{s}(0)=h_{s 0}$.

\section{(3) The vertical infiltration of cesium in the soils}

We discuss the vertical infiltration of cesium in the soils. We reason the unit conversion from intensity of radioactivity per area $\left(\mathrm{Bq} / \mathrm{m}^{2}\right)$ to the concentration of radioactiv- ity in the soils $(\mathrm{Bq} / \mathrm{kg})$. It is reported that cesium remains the shallow topsoils ${ }^{10), 11)}$. If we can know the infiltration depth pf cesium on the topsoils $l(\mathrm{~m})$ and the unit weight of the soils $\rho\left(\mathrm{kg} / \mathrm{m}^{3}\right)$, then we can obtain the concentration of radioactivity in the soils as:

$\begin{aligned} & \text { The concentration of radio- } \\ & \text { activity in the soils }\end{aligned}(\mathrm{Bq} / \mathrm{kg})=\frac{h_{s}(t)\left(\mathrm{Bq} / \mathrm{m}^{2}\right)}{\rho\left(\mathrm{kg} / \mathrm{m}^{3}\right) l(\mathrm{~m})}$.

Eq.(9) describes the unit conversion from intensity of radioactivity per area $\left(\mathrm{Bq} / \mathrm{m}^{2}\right)$ to the concentration of radioactivity in the soils $(\mathrm{Bq} / \mathrm{kg})$.

\section{(4) Transfer factor of radiocesium from the soils to pol- ished rice}

From the definition of the transfer factor Eq.(1),

$\begin{aligned} & \text { The concentration of radio- } \\ & \text { activity in the polished rice }\end{aligned}(\mathrm{Bq} / \mathrm{kg})=\eta \frac{h_{s}(t)}{\rho l}$.

The specific value of $\eta$ is referenced previous studies $^{4), 5), 6), 12)}$.

\section{(5) The annual intake of radioactivity on the rice}

If we can know the average annual rice consumption per capita of Japanese adults $\kappa(\mathrm{kg} / \mathrm{y})$, then we can obtain the annual intake of radioactivity on the rice $r_{i}(t)$ as:

$$
r_{i}(t)=\kappa \eta \frac{h_{s}(t)}{\rho l}(\mathrm{~Bq} / \mathrm{y}) .
$$

We denote Eq.(11) as:

$$
r_{i}(t)=\lambda h_{s}(t),
$$

where $\lambda=\kappa \eta / \rho l$. Thus, the annual intake of radioactivity on the rice $r_{i}(t)$ is proportional to radioactivity on the soils $h_{s}(t)$ for the proportionality coefficient $\lambda\left(\mathrm{m}^{2} / \mathrm{y}\right)$.

\section{(6) Mathematical description of transfer from radioac- tive fallout to radioactivity on polished rice}

Our previous study ${ }^{2)}$ describes the intensity of radioactivity in the human body $h_{b}(t)(\mathrm{Bq} /$ body) by the following continuity equation:

$$
\frac{d h_{b}(t)}{d t}=r_{i}(t)-\alpha_{e} h_{b}(t)
$$

where $\alpha_{e}=\ln 2 / T_{e}$, and $T_{e}$ is the effective half-life. As shown in Fig.2(e), the effective runoff of radioactivity in the human body $q_{e}(t)$ is described as:

$$
q_{e}(t)=q_{p ; b}(t)+q_{b}(t)=\left(\alpha_{p}+\alpha_{b}\right) h_{b}(t)=\alpha_{e} h_{b}(t),
$$

that is, the effective half-life $T_{e}$ satisfies

$$
\frac{1}{T_{e}}=\frac{1}{T_{p}}+\frac{1}{T_{b}}
$$

Solving Eq.(13), we can get $h_{b}(t)$ analytically as a func- 


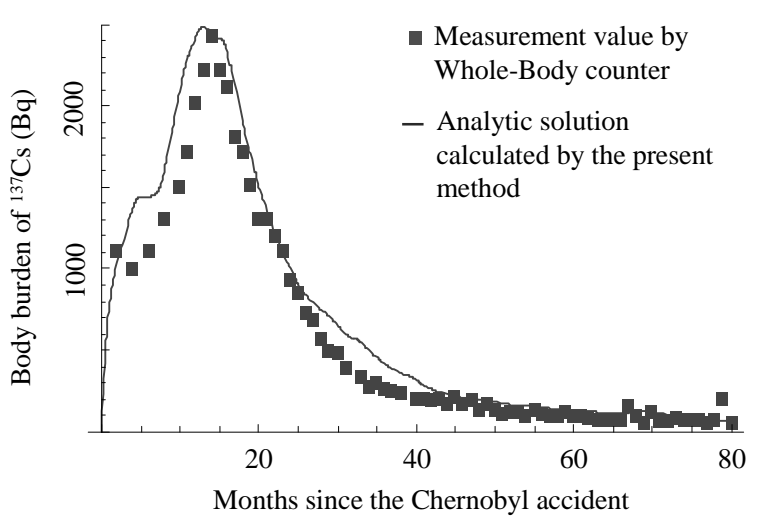

Fig.3 Typical ${ }^{137} \mathrm{Cs}$ body burden of a male. Plots are measurement values using a whole-body counter according to Rühm et al., 1999 ${ }^{13)}$. The solid line is the analytic solution provided by interpolation of the mean time-related intake, calculated by our method (reproduction of Sasaki et al. (2014) Fig. 4(b) ${ }^{2)}$ ).

tion of time $t$ as:

$$
h_{b}(t)=\int_{0}^{t} e^{-\alpha_{e}(t-\tau)} r_{i}(\tau) d \tau
$$

under the initial condition $h_{b}(0)=0$.

An accuracy of our method to calculate the intensity of radioactivity in the human body is reconfirmed. The plots in Fig. 3 measure the ${ }^{137} \mathrm{Cs}$ body burden of a male after the Chernobyl accident using a whole-body counter (readout from Rühm et al. 1999; Fig. 1). The solid line in Fig. 3 is the analytic solution calculated by our method (see Sasaki et al. 2014 ${ }^{2}$ in detail.). It is noted that Fig.3 is reproductions of Fig. 4 in Sasaki et al. 2014²).

Internal total exposure is obtained from time integration of $h_{b}(t)$ as (see Eq. (21) in Sasaki et al. 2014')

$$
I(t)=\int_{0}^{t} h_{b}(\tau) d \tau(\text { atoms } / \text { body }) .
$$

The effective dose $H_{\text {eff }}$ is described as:

$$
H_{\mathrm{eff}}(t)=\frac{I(t) \times\langle E\rangle(\mathrm{MeV}) \times 1.6 \times 10^{-13}(\mathrm{~J} / \mathrm{MeV})}{\text { weight }(\mathrm{kg})}(\mathrm{Sv}),
$$

for radiocesium (see Eq. (16) in Yamada et al. 2013, in detail). $\langle E\rangle$ is the the energy absorbed into the human body per one radioactive decay event. Eq.(18) is, to be exact, the absorbed dose. However, the effective dose and the absorbed dose are equivalent in the case of radiocesium because it occurs $\beta$ decay and distributes whole the body evenly ${ }^{14)}$. In the followings, we treat both are equivalent without notice. Fig.4 compares values of committed effective dose coefficient calculated by our method ${ }^{1)}$ with those determined according to previous study of International Commission on Radiological Protection ${ }^{15)}$ (ICRP). The accuracy of our method to calculate the effective dose is demonstrated regarding nine nuclides. We required special relativity $^{16)}$ and Fermi's interaction ${ }^{17), 18)}$ to estimate

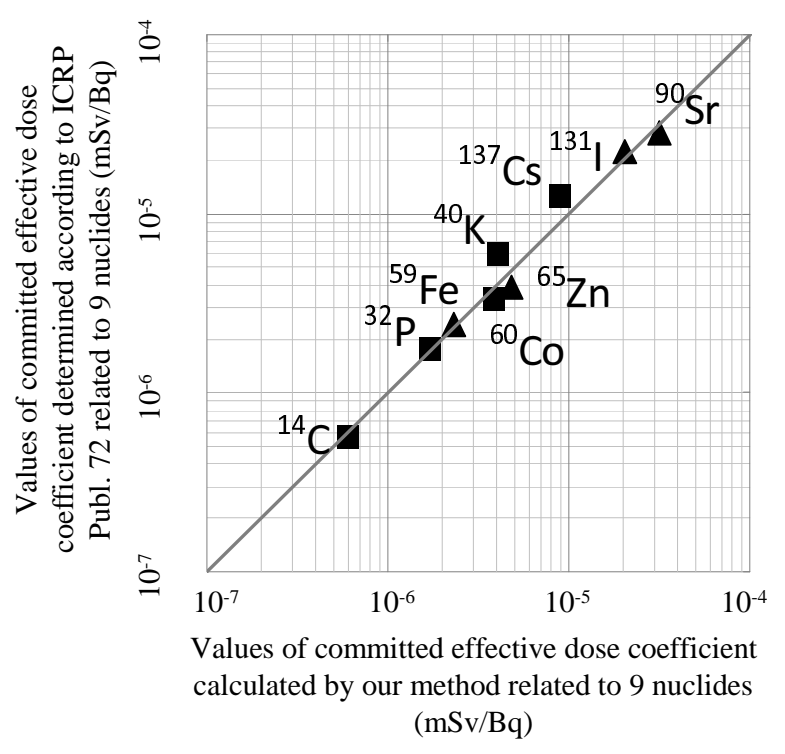

Fig.4 Comparison of the committed effective dose coefficient from previous research (ICRP) with our method(reproduction of Yamada et al. (2013) Fig. 8(c) ${ }^{1)}$ ).

Table 1 The parameters regarding $T_{r}, l, \rho, \eta$ and $\kappa$ used for specific calculation

\begin{tabular}{|c|c|c|}
\hline \multicolumn{1}{|c|}{ The parameter } & Symbol & The value \\
\hline Residence half-time & $T_{r}$ & $18.1 \mathrm{y}$ \\
\hline $\begin{array}{l}\text { Infiltration depth of ce- } \\
\text { sium on the topsoils }\end{array}$ & $l$ & $0.03 \mathrm{~m}$ \\
\hline Unit weight of the soils & $\rho$ & $2000 \mathrm{~kg} / \mathrm{m}^{3}$ \\
\hline $\begin{array}{l}\text { Transfer factor from the } \\
\text { soils to rice }\end{array}$ & $\eta$ & $0.01,0.1,0.4$ \\
\hline $\begin{array}{l}\text { Average annual rice con- } \\
\text { sumption per capita of } \\
\text { Japanese adults }\end{array}$ & $\kappa$ & $60 \mathrm{~kg} / \mathrm{y}$ \\
\hline
\end{tabular}

the energy of $\beta$ ray and $\gamma$ ray concomitant with $\beta$ decay.

Table 1 shows the parameters regarding $T_{r}, l, \rho, \eta$ and $\kappa$ used for concrete calculation. The parameters are justified by the below references. Residence half-time $T_{r}=18.1$ (year) is average across Japan ${ }^{9)}$. It is employed as a typical example. Tanihata ${ }^{11)}$ suggests that the depth which the radioactivity of radiocesium decreases to one-tenth is $31 \mathrm{~mm}$, and so we employ the infiltration depth of cesium on the topsoils as $l=0.03 \mathrm{~m}$. The unit weight of the soils $\rho=2000 \mathrm{~kg} / \mathrm{m}^{3}$ is represent value for convenience. For example, Braja ${ }^{19)}$ notes that The unit weight of the soils is $1970.3 \mathrm{~kg} / \mathrm{m}^{3}$. It is known that the transfer factor from the soils to rice $\eta$ is fluctuated due to the environmental factors ${ }^{4), 5), 6)}$. National Institute for AgroEnvironmental Sciences reports that the range of transfer factor is $3 \times 10^{-4} \leq \eta \leq 0.18^{12)}$, and the average is $2.6 \times 10^{-3}$. Here, we assume $\eta=0.01,0.1,0.4$, as plausi- 


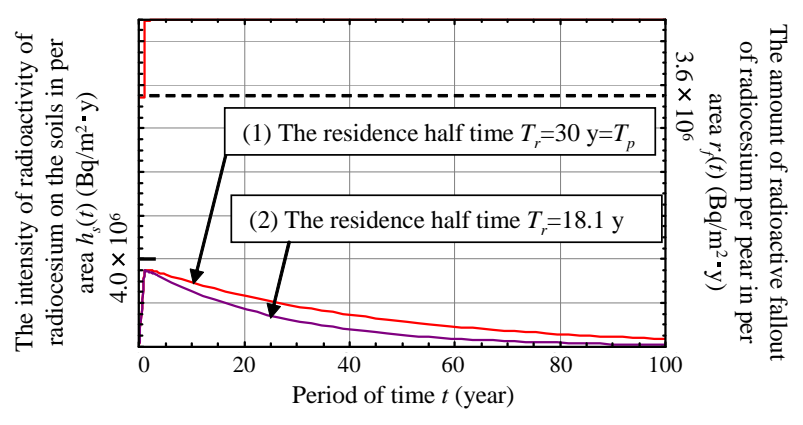

Fig.5 The time series of the annual amount of radiocesium fallout and the intensity of radioactivity per area on the soil $h_{s}(t)$.

ble values. In the case of $\eta=0.4$, it is larger than double of the maximum measurement value. We can say that we estimate sufficiently more unsafe dose when $\eta=0.4$. The average annual rice consumption of Japanese adults $\kappa$ is referenced Abdullah ${ }^{20)}$, set to be $60 \mathrm{~kg} / \mathrm{y}$.

Then, the proportionality coefficient $\lambda$ is branched as:

$$
\lambda=\left\{\begin{array}{lll}
0.01 \quad \mathrm{~m}^{2} / \mathrm{y} & (\eta=0.01) \\
0.1 \quad \mathrm{~m}^{2} / \mathrm{y} & (\eta=0.1) \\
0.4 \mathrm{~m}^{2} / \mathrm{y} & (\eta=0.4)
\end{array} .\right.
$$

\section{Results and Discussion}

\section{(1) The calculation of radioactivity on the soil using the measured fallout}

Fig. 5 shows the time series of the annual amount of radiocesium fallout and the intensity of radioactivity per area on the soil. The annual amount of radioactive fallout is estimated by the summation of measured monthly amount of fallout ${ }^{3}$. It should be noticed that the annual amount of fallout after the April 2014 (i.e. $t>3$ ) is extrapolated. Fig. 5 suggests that almost fallout had fallen with in 1 year after the accident.

Fig.5 (1) shows the intensity of radioactivity per area on the soil $h_{s}(t)$ in the case of the residence half-time $T_{r}=T_{p}=30 \mathrm{y}$, that is, the case runoff emerges from environmental factors are neglected. It is the improbable case realistically. We can also say Fig.5 (1) is maximum intensity of radioactivity.

Fig.5 (2) shows the intensity of radioactivity per area on the soil $h_{s}(t)$ in the case of the residence half-time $T_{r}=$ $18.1 \mathrm{y}$. It is the average of Japan ${ }^{9)}$ as mentioned above. Here, we employ the value as a typical example. In the followings, we discuss using the solution of the intensity of radioactivity per area on the soil $h_{s}(t)$ shown in Fig.5 (2).

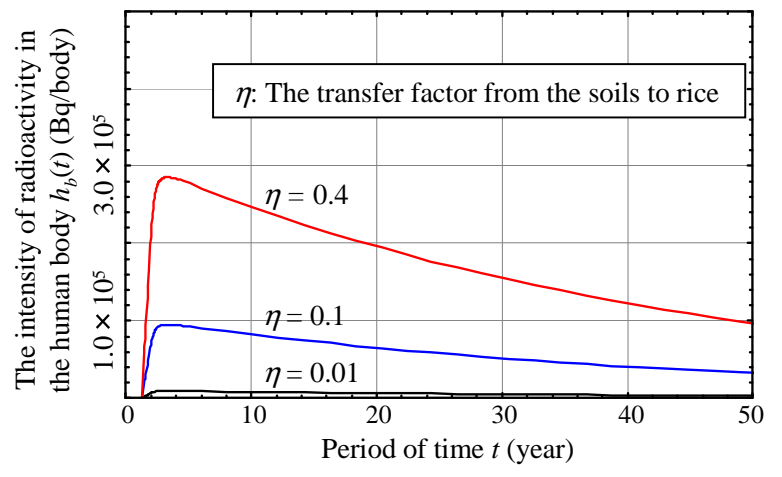

Fig.6 The time series of the intensity of radioactivity in the human body $h_{b}(t)$ according to the transfer factor $\eta$.

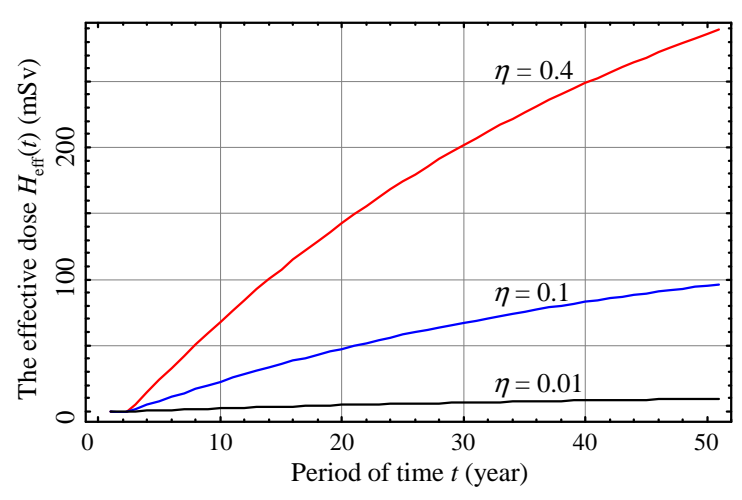

Fig.7 The time series of the effective dose according to the transfer factor $\eta$.

(2) Radioactivity in the human body caused by the intake of radiocesium on the polished rice

The relationship between $h_{s}(t)$ with $r_{i}(t)$ is described in Eq.(12). Substituting Eq.(12) into Eq.(13), we can get the intensity of radioactivity in the human body $h_{b}(t)$. Fig.6 shows the time series of $h_{b}(t)$ according to the transfer factor $\eta$. In the next section, we calculate the effective dose based on the result shown in Fig.6.

\section{(3) The effective dose calculation due to the intake of radioactivity on the rice derived from fallout}

Substituting the solution of Eq.(13) into Eq.(17), internal total exposure $I(t)$ is obtained. Subsequently, substituting $I(t)$ into Eq.(18), we can get the effective dose $H_{\text {eff }}(t)$. Fig.7 shows the time series of the effective dose according to $\eta$. If $\eta=0.4$, the dose rate is $5.8 \mathrm{mSv} / \mathrm{y}$. We should notice that this calculation excluding artificial decontamination activity completely. It should be noted that the rice exceeds the standard limit for radiocesium in Japan (100 $\mathrm{Bq} / \mathrm{kg}$ ) is not on the market.

For reference to compare, the United Nations Scientific Committee on the Effects of Atomic Radiation (UNSCEAR) states that the total exposure dose due to natural radiation (world average) is $2.4 \mathrm{mSv} / \mathrm{y}^{21)}$. UNSCEAR also 
noted that a dose rate less than $100 \mathrm{mSv} / \mathrm{y}$ indicates a linear no-threshold model ${ }^{22}$. It is said that the dose rate does not provide a significant indication of cancer risk ${ }^{23)}$. We can say that the order of dose rate caused by the intake of radioactivity on the rice is same with those of natural radiation in the case of $\eta=0.4$.

\section{Conclusion}

The objective of this paper was to calculate the effective dose due to the intake of radioactivity on agricultural products derived from fallout. Radioactivity on the soils $h_{s}(t)$ is described as a single vessel as with the human body. We can get $h_{s}(t)$ analytically solving continuity equation of radioactivity, which is the first order differential equation. We discuss the transfer of radiocesium from the soils to the rice based on previous studies. Thus, we calculate the effective dose using our previously proposed method. The scope of our research is expanded from the human body to the soils. We calculate the effective dose due to the intake of the rice in the case of there is no artificial decontamination. In the case of the transfer factor $\eta$ is larger than double of the maximum measure value, the order of the dose rate is same with those of natural radiation.

ACKNOWLEDGMENT: This work was partially supported by MEXT KAKENHI Grant Number 26249072, Research Program on Climate Change Adaptation, MEXT, Japan (MEXT/RECCA), and the MEXT/SOUSEI program (theme C-i-C).

\section{REFERENCES}

1) Yamada, T., Yamada, T.J., Sasaki, S., Introduction to Radiological Hydrology: A Kinematic Model to Estimate the Effective Dose of Radioactive Substances in the Human Body for Radiological Protection, Proceedings of 2013 IAHR World Congress, Z1003 (2013).

2) Sasaki, S., Yamada, T., Yamada, T.J., Proposal of a hydrological model to estimate a number of radioactive atoms in the human body, radioactivity and internal total exposure caused by ingestion of radioactive isotopes, J. Japan Soc. Hydrol. and Water Resor. Vol. 27, No. 4, pp. 170-181, 2014 (in Japanese).

3) Nuclear Regulation Authority, Monitoring information of environmental radioactivity level, http://radioactivity. nsr.go.jp/en/, 2014.

4) Yamaguchi, N. et al., Behavior of radiocesium in soil-plant systems and its controlling factor, Bull. Natl. Inst. AgroEnviron. Sci., Vol. 31, pp. 75-129, 2012 (in Japanese).

5) Ochiai, T., Takeda, S., Kimura, H., Database on Soil-to-Plant Transfer Factors for the Safety Assessment of Geological Disposal, Bull. Natl. Inst. Agro-Environ. Sci., Vol. 31, pp. 75129, 2009 (in Japanese).
6) International Atomic Energy Agency, Handbook of Parameter Values for the Prediction of Radionuclide Transfer in Terrestrial and Fresh Water Environment, Technical Reports Series, 472, 1-194, 2010.

7) Komamura, M., Tsumura, A., and Kodaira, K., Residence half-time of ${ }^{137} \mathrm{Cs}$ in Japanese Paddy and upland fields, JAERI-Conf., 99-001, 12-23, 1998 (in Japanese).

8) Komamura, M., Tsumura, A., and Kodaira, K., Residence half-time of ${ }^{137} \mathrm{Cs}$ in Japanese Paddy Top-soils, RADIOISOTOPES, 48, 635-644, 1999 (in Japanese).

9) Komamura, M. et al., Long-term Modeling and Analysis of ${ }^{90} \mathrm{Sr}$ and ${ }^{137} \mathrm{Cs}$ Concentrations in Rice in Japan from 1959 to 2000, Bull. Natl. Inst. Agro-Environ. Sci., Vol. 24, pp. 1-21, 2006 (in Japanese).

10) Nogawa, N. et. al., Extraction of ${ }^{137} \mathrm{Cs},{ }^{134} \mathrm{Cs}$ and ${ }^{131} \mathrm{I}$ from Radioactive soils in Fukushima, RADIOISOTOPES, 60, 311315, 2011 (in Japanese).

11) Tanihata, I., Sampling and Mapping of Soil Contamination and What We Have Learn from It, RADIOISOTOPES, 62, 724-740, 2013 (in Japanese).

12) National Institute for Agro-Environmental Sciences, Bulletin of National Institute for Agro-Environmental Sciences, http://www .niaes .affrc.go.jp/sinfo/result/ result14/result14_38.html, 1997 (in Japanese).

13) W. Rühm, K. König, and A. Bayer. Long-term follow-up of the ${ }^{137} \mathrm{Cs}$ body burden of individuals after the Chernobyl accident - A means for the determination of biological half-lives, Health Physics 77, 373-382, 1999.

14) Bunker A., The ICRP database of dose coefficients: workers and members of the public, Journal of Radiological Protection, 19, 290, 1999.

15) International Commission on Radiological Protection, Agedependent Doses to the Members of the Public from Intake of Radionuclides - Part 5 Compilation of Ingestion and Inhalation Coefficients, Ann. ICRP, 26 (1), 1995.

16) Einstein, A., On the Electrodynamics of Moving Bodies, Annalen der Physik, 322 (10), 891-921, 1905 (in German).

17) Fermi, E., Tentativo di una teoria dei raggi $\beta$, Il Nuovo Cimento, 11 (1), 1-19. 1933 (in Italian).

18) Fermi, E., Nuclear physics, The University of Chicago Press, 1951.

19) Braja, D., Fundamentals of Geotechnical Engineering fourth edition, Cengage Learning, 2012.

20) Abdullah, A. B., Ito, S., Adhana, K., Estimate of Rice Consumption in Asian Countries and the World Towards 2050, International Rice Research Institute, http://worldfood. apionet.or.jp/alias.pdf, 2005.

21) United Nations Scientific Committee on the Effects of Atomic Radiation, UNSCEAR 2008 REPORT Vol. I; Sources and effects of ionizing radiation, United Nations, 2010.

22) United Nations Scientific Committee on the Effects of Atomic Radiation, Fifty-seventh session, includes Scientific Report: summary of low-dose radiation effects on health, United Nations, 2011

23) International Commission on Radiological Protection, The 2007 Recommendations of the International Commission on Radiological Protection, Ann. ICRP, 37 (2-4), 2007.

(Received September 30, 2014) 